\title{
Oncogene Lin28B increases chemosensitivity of colon cancer cells in a let-7-independent manner
}

\author{
LIHONG MA $^{1}$, QI ZHAO ${ }^{1}$, WENHAO CHEN $^{2}$ and YANQIAO ZHANG ${ }^{3}$ \\ ${ }^{1}$ Outpatient Department of Chemotherapy, Affiliated Tumor Hospital of Harbin Medical University, Harbin, \\ Heilongjiang 150040; ${ }^{2}$ Institute of Mental Health, Peking University Sixth Hospital, Beijing 100191; \\ ${ }^{3}$ Department of Gastrointestinal Medical Oncology, Affiliated Tumor Hospital of \\ Harbin Medical University, Harbin, Heilongjiang 150040, P.R. China
}

Received January 9, 2016; Accepted May 18, 2017

DOI: $10.3892 / \mathrm{ol} .2018 .8250$

\begin{abstract}
Lin-28 homolog B (Lin28B) is a RNA binding protein conserved between Caenorhabditis elegans and humans, and it has important roles in regulating development. The overexpression of Lin28B has been observed in various human malignant tumors and the upregulation of Lin28B predicts tumor progression and/or poor prognosis. The majority of studies suggested that Lin $28 \mathrm{~B}$ is an oncogene that promotes the proliferation and metastasis of cancer cells. However, few studies have focused on the function of Lin28B in chemotherapy. In the present study, the role of Lin28B in the chemosensitivity of colon cancer cells to 5-fluorouracil (5-FU) was detected by establishing a Lin28B over-expressing HCT116 (EGFP-Lin28B-HCT116) cell line. In accordance with the immunohistochemistry results, Lin28B-GFP expression was predominantly distributed in the cytoplasm, and the overexpression of Lin28B was confirmed using quantitative polymerase chain reaction and western blot analysis. The control EGFP-HCT116 and Lin28B over-expressing EGFP-Lin28B-HCT116 cells were then exposed to various concentrations of 5-FU for $48 \mathrm{~h}$. A luminescence-based cell viability assay was used to detect the effect of Lin28B on the chemotherapeutic sensitivity of colon cancer cells. It was demonstrated that overexpression of Lin28B improved the chemotherapeutic sensitivity of colon cancer cells to 5-FU. Additional investigation revealed that Lin28B enhanced the chemosensitivity of colon cancer cells by promoting cell apoptosis induced by 5-FU; however, this effect was independent of Lin28B inhibiting the biogenesis of let-7, the well-known target of Lin28B. The mechanism of this effect of Lin28B on the chemosensitivity of cells requires additional investigation. The present study suggested that Lin28B may
\end{abstract}

Correspondence to: Professor Yanqiao Zhang, Department of Gastrointestinal Medical Oncology, Affiliated Tumor Hospital of Harbin Medical University, 150 Haping Road, Harbin, Heilongjiang 150040, P.R. China

E-mail: zhangyanqiao@ems.hrbmu.edu.cn

Key words: colon cancer, Lin28B, chemosensitivity, apoptosis, let-7 act as a biomarker for predicting chemotherapy sensitivity in patients with colon cancer.

\section{Introduction}

Colorectal cancer is one of the most common malignant tumors worldwide. However, the treatment of colon cancer remains unsatisfactory due to chemoresistance (1).

Lin-28 homolog B (Lin28B) is a conserved RNA-binding protein. It was originally identified in hepatocellular carcinoma, where the protein encoded by this gene is highly increased (2). This protein has been identified to majorly distribute in the cellular nucleus (3). Previously, in addition to hepatocellular carcinoma, numerous studies have indicated that Lin28B is frequently upregulated in various cancers, including colon cancer, and the elevated expression of the protein is associated with advanced tumor stage and poor prognosis (4-6). The mechanisms involved in the promotion of the development of human malignant tumors by upregulated Lin28B include promoting cellular proliferation, angiogenesis and metastasis, facilitating tumor-associated inflammation, reprogramming metabolism, acquiring immortality and evading immune destruction. This may occur by either repressing the generation of let-7, a well-studied miRNA with tumor suppressor function, or stabilizing the oncogenic transcripts, such as cell cycle proteins, cyclin-dependent kinases, growth factors and ribosomal proteins (7).

Although it has been reported that Lin28B promotes colon cancer growth, migration and recurrence $(8,9)$, the function of Lin28B in colon cancer chemotherapy remains unknown. In the present study, the expression of Lin28B in colon cancer tissues and the effect of Lin28B on the chemosensitivity of colon cancer cells to 5-fluorouracil (5-FU) were detected. Additionally, the potential mechanism of Lin28B affecting chemotherapeutic sensitivity of colon cancer cells to 5-FU was also explored.

\section{Materials and methods}

Cell culture. The colon cancer HCT116 cell line and human embryonic nephral epithelia 293TN cell line, which was used for lentiviral vector packaging, were maintained in Dulbecco's modified Eagle medium (HyClone; GE Healthcare Life 
Sciences, Logan, UT, USA) supplemented with $10 \%$ fetal bovine serum (Invitrogen; Thermo Fisher Scientific, Inc., Waltham, MA, USA) at $37^{\circ} \mathrm{C}$ in a humidified atmosphere containing $5 \% \mathrm{CO}_{2}$.

Human tissues and immunohistochemistry. A total of 103 formalin-fixed paraffin-embedded tissues, consisting of 92 colon cancer tissues and 11 adjacent mucosa tissues obtained from colon cancer patients that underwent resection of colon carcinoma at the Affiliated Tumor Hospital of Harbin Medical University between May 2011 and July 2012. The diagnoses for all samples were confirmed by two or more pathologists. The present study was approved by the Ethical Committee of Harbin Medical University (Harbin, China). All patients provided informed consent prior to surgery.

Immunohistochemistry was used to detect the expression of Lin28B in colon cancer tissues or adjacent colon tissues. Briefly, $5-\mu \mathrm{m}$-thick sections were prepared from paraffin-embedded tissues. Sections were rehydrated using a gradient alcohol series, as follows: $100 \%$ ethanol for $10 \mathrm{~min}$ twice; $95 \%$ ethanol for $5 \mathrm{~min}$; $80 \%$ ethanol for $5 \mathrm{~min}$; and $70 \%$ ethanol for $5 \mathrm{~min}$ at room temperature. Next, the sections were placed in citrate buffer ( $\mathrm{pH}$ 6.0) and heated in a microwave oven for antigen retrieval $\left(95^{\circ} \mathrm{C}\right.$ for $\left.3 \mathrm{~min}\right)$. Endogenous peroxidase activity was inhibited by incubation in $3 \%$ hydrogen peroxide for 15 min. Following blocking with 5\% bovine serum albumin (Sigma-Aldrich; Merck KGaA, Darmstadt, Germany) for $1 \mathrm{~h}$ at room temperature, sections were incubated with primary antibodies against Lin28B (1:1,000; cat. no. ab115698; Abcam, Cambridge, MA, USA), overnight at $4^{\circ} \mathrm{C}$. Subsequently, the sections were incubated with the secondary streptavidin-biotin peroxidase-conjugated antibody (1:1,000; cat. no. ab6721; Abcam) for $1 \mathrm{~h}$ at room temperature, and 3,3'-diaminobenzidine (Origene Technologies, Inc., Beijing, China) was used to stain the sections. The evaluation of Lin28B expression was performed by a pathologist under light microscopic observation (magnification, $\mathrm{x} 400$ ), as previously described (10).

Pseudo lentivirus packaging and transduction into cells. Lin28B over-expressed lentiviral vectors were constructed and the pseudo lentivirus was packaged as described previously (11). To generate Lin28B overexpression of lentiviral vectors, the open reading frame of Lin28B was amplified by $2 \mathrm{X}$ EasyTaq PCR SuperMix for PAGE (Beijing Transgen Biotech Co., Ltd., Beijing, China) from HCT116 cells. The polymerase chain reaction (PCR) assays using DNA from HCT116 cells were performed at $95^{\circ} \mathrm{C}$ for $5 \mathrm{~min}$ and then 40 cycles of denaturation at $95^{\circ} \mathrm{C}$ for $10 \mathrm{sec}$, amplification at $60^{\circ} \mathrm{C}$ for $30 \mathrm{sec}$ and extension at $72^{\circ} \mathrm{C}$ for $1 \mathrm{~min}$. The DNA polymerase was purchased from Beijing Transgen Biotech Co. Ltd. (2X EasyTaq PCR SuperMix; cat. no. AS111-11; Beijing, China). Primer sequences are summarized in Table I. Subsequent to sequencing and digestion with $B a m \mathrm{H} 1$ and $M l u 1$, the vector was inserted into a pWPXL lentiviral construction plasmid (cat. no. 12257; Addgene, Inc., Cambridge, MA, USA). The recombinant plasmid and packaging plasmids psPAX2 (cat. no. 12260; Addgene) and PMD.2G (cat. no. 12259; Addgene) were co-transfected into $293 \mathrm{TN}$ cells. The transfection was mediated using Lipofectamine 2000 (Invitrogen; Thermo Fisher Scientific, Inc.) according to the manufacturer's protocol.
At $48 \mathrm{~h}$ subsequent to transfection, the supernatant was collected and the lentivirus was condensed using polyethylene glycol reagent (System Biosciences, Palo Alto, CA, USA) according to the manufacturer's instructions. To generate cells with stable Lin28B overexpression, HCT116 cells were incubated with $10 \mathrm{MOI}$ of control lentiviral particles or Lin28B overexpression lentiviral particles for at least $12 \mathrm{~h}$ at $37^{\circ} \mathrm{C}$ in a humidified atmosphere containing $5 \% \mathrm{CO}_{2}$, subsequent to culturing for at least $72 \mathrm{~h}$. GFP-positive cells were then identified by assessing the relative fluorescence intensities using the FACSAria II flow cytometer and analyzed with FACSDiva software 6.1.3 (BD Biosciences, Franklin Lakes, CA, USA).

RNA isolation and quantitative PCR. Total RNA was extracted from HCT116 cells using TRIzol reagent (Invitrogen; Thermo Fisher Scientific, Inc.) and cDNA was synthesized by using a high-capacity cDNA reverse transcriptase kit (Applied Biosystems; Thermo Fisher Scientific, Inc.) as previously described (12), with random primers or specific miRNA reverse transcription primers. The relative RNA expression was detected using the SYBR Green quantitative PCR reagent (Beijing Transgen Biotech, Inc.). Gene expression was analyzed using the $2^{-\Delta \Delta \mathrm{Cq}}$ method (13). The PCR reactions consisted of the following conditions: $95^{\circ} \mathrm{C}$ for $5 \mathrm{~min}$, followed by 40 cycles of amplification at $95^{\circ} \mathrm{C}$ for $10 \mathrm{sec}$ and $60^{\circ} \mathrm{C}$ for $30 \mathrm{sec}$. The primer sequences used for reverse transcription and quantitative PCR are stated in Table I.

Transfection. A total of $50 \mathrm{nM}$ of microRNA negative control (NC; sequence, ucaccuagaagcuaguuaacag) and let-7 mimic (sequence, ugagguaguagguuguauaguu) were synthesized by GE Dharmacon (GE Healthcare Life Sciences). Transfection was performed using GE Dharmacon DharmaFECT kb DNA transfection reagent (GE Healthcare Life Sciences), according to the manufacturer's protocol.

Cell viability assay. In total, $5 \times 10^{3}$ HCT116 cells were seeded onto a 96-well plate and treated with 80,160,320 and $640 \mu \mathrm{M}$ 5-FU (Jinyao Amino Acid Co., Ltd, Tianjin, China) for $48 \mathrm{~h}$. Cellular viability was measured using CellTiter-Glo reagent (Promega Corp., Madison, WI, USA), according to the manufacturer's instructions. Briefly, $100 \mu \mathrm{l}$ CellTiter-Glo reagent was added to each well, and the plate was equilibrated at room temperature for $30 \mathrm{~min}$. The contents were then mixed on an orbital shaker. Finally, the value of luminescence was measured at $460 \mathrm{~nm}$, and the value was normalized to blank control.

Apoptosis analysis. Cell apoptosis was detected using the Phycoerythrin (PE)-Annexin V Apoptosis Detection kit (BD Biosciences), according to the manufacturer's instructions. Briefly, $1 \times 10^{6}$ cells were collected, and then washed with PBS and re-suspended in1mlbinding buffer. Subsequently, $100 \mu \mathrm{l}$ solution ( $1 \times 10^{5}$ cells) was transferred to a 5-ml culture tube, and $5 \mu \mathrm{l} \mathrm{PE}$-annexin $\mathrm{V}$ and $5 \mu \mathrm{l}$ 7-ADD were then added to the tube. The cells were vortexed gently and incubated for $10 \mathrm{~min}$ in the dark at room temperature. Finally, $400 \mu 1$ binding buffer was added to each tube before analyzing the tubes by flow cytometry.

Western blot analysis. The total proteins were extracted from cells using radioimmunoprecipitation assay lysis buffer 
Table I. Primer sequences used in the present study.

Primer name
Primer sequence $\left(5^{\prime}-3^{\prime}\right)$
Let-7a RT

Let-7b RT

Let-7c RT

U6 RT

Let-7a quantitative PCR

Forward

Reverse

Let-7b quantitative PCR

Forward

Reverse

U6

Forward

Reverse

Let-7c quantitative PCR

Forward

Reverse

GAPDH

Forward

Reverse

Lin28B

Forward

Reverse
GTCGTATCCAGTGCAGGGTCCGAGGTATTCGCACTGGATACGACaactat GTCGTATCCAGTGCAGGGTCCGAGGTATTCGCACTGGATACGACaaccac GTCGTATCCAGTGCAGGGTCCGAGGTATTCGCACTGGATACGACaaccat AAAATATGGAACGCTTCACGAATTTG

TGAGGTAGTAGGTTG

GTCGTATCCAGTGCAGGGTCCGAGGT

\author{
TGAGGTAGTAGGTTGTGT \\ GTCGTATCCAGTGCAGGGTCCGAGGT
}

\author{
CTCGCTTCGGCAGCACATATACT \\ ACGCTTCACGAATTTGCGTGTC
}

TGAGGTAGTAGGTTGTATt

GTCGTATCCAGTGCAGGGTCCGAGGT

\author{
ATGGGGAAGGTGAAGGTCG \\ GGGGTCATTGATGGCAACAATA
}

GTCAATACGGGTAACAGGAC

TTCTTTGGCTGAGGAGGTAG

RT, reverse transcription; PCR, polymerase chain reaction; Lin28B, Lin-28 homolog B.

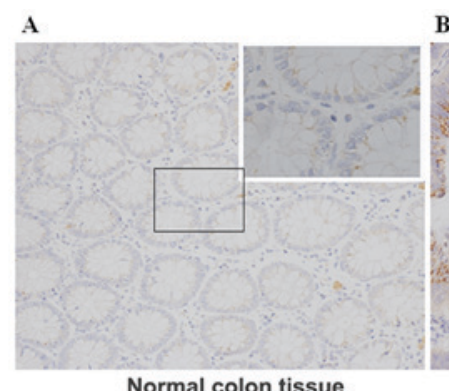

Normal colon tissue
B

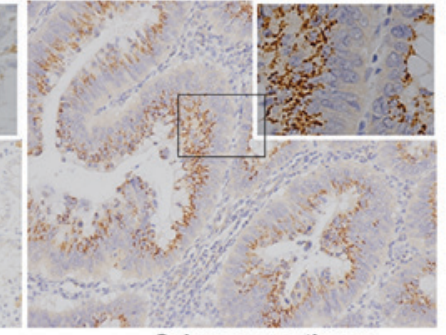

Colon cancer tissue

Figure 1. Lin28B was upregulated in colon cancer tissues, as detected by immunohistochemical staining (magnification, x100). The magnification in the top-right corner of the images is $\mathrm{x} 400$. (A) Lin28B was not expressed in adjacent colon tissue. (B) Lin28B was expressed in colon cancer tissue. Lin28B, Lin-28 homolog B.

(Beyotime Institute of Biotechnology, Shanghai, China), and subsequently quantified using the Bradford method (Bio-Rad Laboratories, Inc., Hercules, CA, USA). In total, $20 \mu \mathrm{g}$ protein/well was loaded and separated by SDS-PAGE (10\% gel) and then transferred to polyvinylidene difluoride membrane (Bio-Rad Laboratories, Inc.). Subsequent to blocking by $5 \%$ bovine serum albumin (Sigma-Aldrich; Merck KGaA), membranes were incubated with the following primary antibodies at $4^{\circ} \mathrm{C}$ overnight: Rabbit monoclonal Lin28B antibody diluted at 1:1,000 (Abcam) and polyclonal rabbit anti-GAPDH

antibody diluted at 1:5,000 (ab115698; Abcam). The polyvinylidene fluoride membranes were then incubated with peroxidase-conjugated goat anti-rabbit secondary antibody (1:4,000; ab6721; Abcam) for $1 \mathrm{~h}$ after washing with PBST (Phosphate Buffered Saline containing 1\% Tween-20). Finally, proteins were visualized using an enhanced chemiluminescence detection system (Thermo Fisher Scientific, Inc.).

Statistical analysis. All data are expressed as the mean \pm standard deviation. Student's t-test was used to compare the significance of differences between two or more groups, as appropriate. $\mathrm{P}<0.05$ was considered to indicate a statistically significant difference.

\section{Results}

High expression of Lin28B was detected in colon cancer tissues. The expression pattern of Lin28B was investigated in colon cancer. Using immunohistochemistry, the expression of Lin28B was detected in 92 colon cancer tissues and 11 adjacent colon tissues. The results indicated that the Lin $28 \mathrm{~B}$ protein was expressed in all colon cancer tissues, resulting in a positive rate of Lin28B expression of $100 \%$, while only $\sim 9.1 \%$ of adjacent colon tissues expressed Lin28B (1/11) (Fig. 1). As shown in Fig. 1, it was found that Lin28B was mainly expressed in the cytoplasm of cancer cells, which is contrary to previous observation (3). It was reported 
Table II. Association between clinical characteristics and Lin-28 homolog B expression.

\begin{tabular}{|c|c|c|c|}
\hline Clinical parameters & Patients, $\mathrm{n}$ & Immunohistochemistry score ${ }^{a}$ & P-value \\
\hline Age (range, 39-75) & & & $>0.05$ \\
\hline$\leq 50$ years & 39 & $5.3 \pm 1.4$ & \\
\hline$>50$ years & 53 & $4.8 \pm 2.6$ & \\
\hline Sex & & & $>0.05$ \\
\hline Male & 63 & $5.7 \pm 3.4$ & \\
\hline Female & 29 & $3.7 \pm 2.7$ & \\
\hline Morphology & & & $>0.05$ \\
\hline Ulcerated & 15 & $4.7 \pm 2.4$ & \\
\hline Polypous & 73 & $3.8 \pm 2.3$ & \\
\hline Infiltrating & 4 & $4.3 \pm 1.8$ & \\
\hline Differentiation & & & $>0.05$ \\
\hline Well & 21 & $5.4 \pm 3.4$ & \\
\hline Moderate & 49 & $4.3 \pm 1.7$ & \\
\hline Poor & 22 & $5.1 \pm 2.7$ & \\
\hline Lymph node metastasis & & & $>0.05$ \\
\hline Yes & 33 & $5.7 \pm 4.4$ & \\
\hline No & 59 & $4.3 \pm 2.3$ & \\
\hline Tumor size & & & $>0.05$ \\
\hline$\leq 5 \mathrm{~cm}$ & 43 & $4.9 \pm 2.5$ & \\
\hline$>5 \mathrm{~cm}$ & 49 & $5.2 \pm 3.7$ & \\
\hline
\end{tabular}

${ }^{\text {a}}$ Data are presented as the mean \pm standard deviation.

that Lin28B not only promotes the proliferation, but also facilitates the metastasis of cancer cells (4). The association between Lin28B expression and clinical parameters of patients with colon cancer was then analyzed. As shown in Table II, the expression level of Lin28B was not associated with any clinical parameter. Thus, Lin28B was not observed to have an impact on the proliferation and metastasis of colon cancer in the present study.

Overexpression of Lin $28 B$ increased chemotherapeutic sensitivity of colon cancer cells to 5-FU. Since no association was identified between Lin28B expression and tumor size or lymph node metastasis, the impact of Lin28B on the chemotherapeutic sensitivity of colon cancer cells was then detected. To identify the potential role of Lin28B in chemotherapy of colon cancer, a Lin28B over-expressing HCT116 (EGFP-Lin28B-HCT116) cell line was established. In accordance with the immunohistochemistry results, Lin28B-GFP expression was predominantly distributed in the cytoplasm (Fig. 2A), and the overexpression of Lin28B was confirmed using quantitative PCR (Fig. 2B) and western blot analysis (Fig. 2C). The control EGFP-HCT116 and Lin28B over-expressing EGFP-Lin28B-HCT116 cells were then exposed to various concentrations of 5-FU for $48 \mathrm{~h}$. A luminescence-based cell viability assay was used to detect the effect of Lin28B on the chemotherapeutic sensitivity of colon cancer cells. The result showed that, compared with the control cells, the sensitivity of cells with Lin28B overexpression to 5-FU is significantly increased ( $\mathrm{P}<0.01$; Fig. 2D).
Lin28B overexpression promoted the cell apoptosis induced by $5-F U$. To detect the potential mechanism by which Lin28B enhances the chemosensitivity of colon cancer cells to 5-FU, the present study evaluated the effect of Lin28B overexpression on the apoptosis of HCT116 cells induced by 5 -FU. The present results showed that the apoptosis rate of EGFP-Lin28B-HCT116 cells was significantly increased compared with the EGFP-HCT116 cells (student's t-test, $\mathrm{P}<0.05$, Fig. 3). This result suggested that Lin28B may increase the chemosensitivity of colon cancer cells to 5-FU by enhancing cell apoptosis.

Lin28B increased the chemosensitivity of colon cancer cells to $5-F U$ in a let-7 independent manner. It is well known that let-7 is one of the most frequently studied targets of Lin28B. To identify the molecular mechanism by which Lin28B increases the chemosensitivity of colon cancer cells to 5-FU, the potential involvement of let-7 was then evaluated. As expected, the overexpression of Lin28B in HCT116 cells significantly inhibited the expression of let-7 (Fig. 4A), which is consistent with previous studies (14). Subsequently, the effect of let-7 on colon cancer chemotherapy was investigated. It was shown that the overexpression of let-7b in HCT116 cells significantly enhanced the chemosensitivity of colon cancer cells to 5-FU ( $\mathrm{P}<0.01$; Fig. 4B). This result is same as the effect of Lin28B on the chemotherapy of colon cancer treatment with 5-FU, even though the overexpression of Lin28B significantly inhibits the expression of let-7. Overall, these results indicated that Lin28B increased the chemosensitivity of colon cancer cells to 5-FU in a let-7 independent manner. 
A
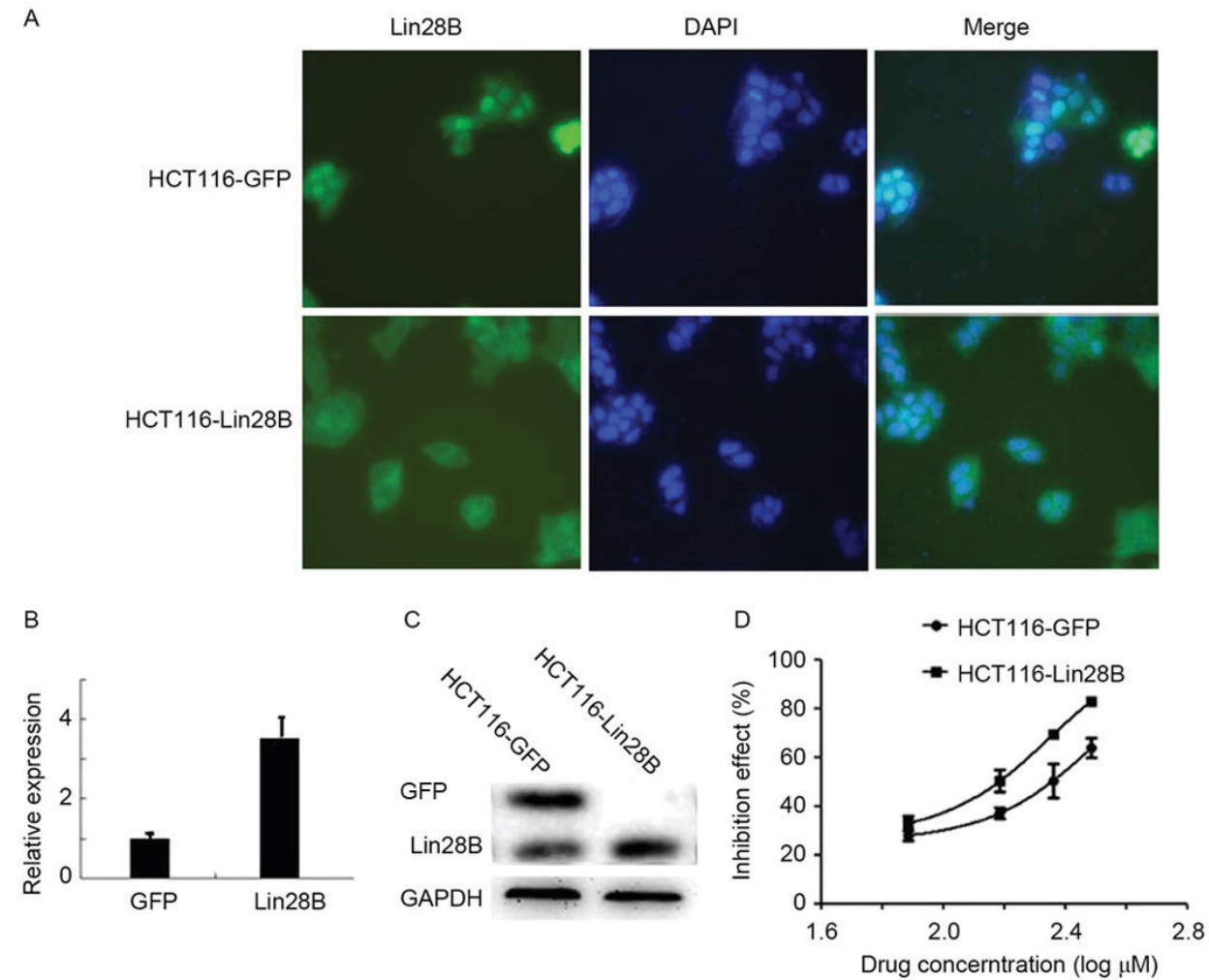

Figure 2. Overexpression of Lin28B promotes the chemotherapeutic sensitivity of colon cancer cells to 5-FU. (A) Lin28B was predominantly located in the cytoplasm of HCT116 cells, as illustrated by GFP distribution, and the nucleus was stained by DAPI (magnification, x200). (B) Overexpression of Lin28B was confirmed by quantitative polymerase chain reaction. (C) Overexpression of Lin28B was confirmed by western blot analysis. (D) The overexpression of Lin28B significantly increased the chemosensitivity of HCT116 cells treated with 5-FU ( $\mathrm{P}<0.05)$. Lin28B, Lin-28 homolog B; 5-FU, 5-fluorouracil; GFP, green fluorescent protein.
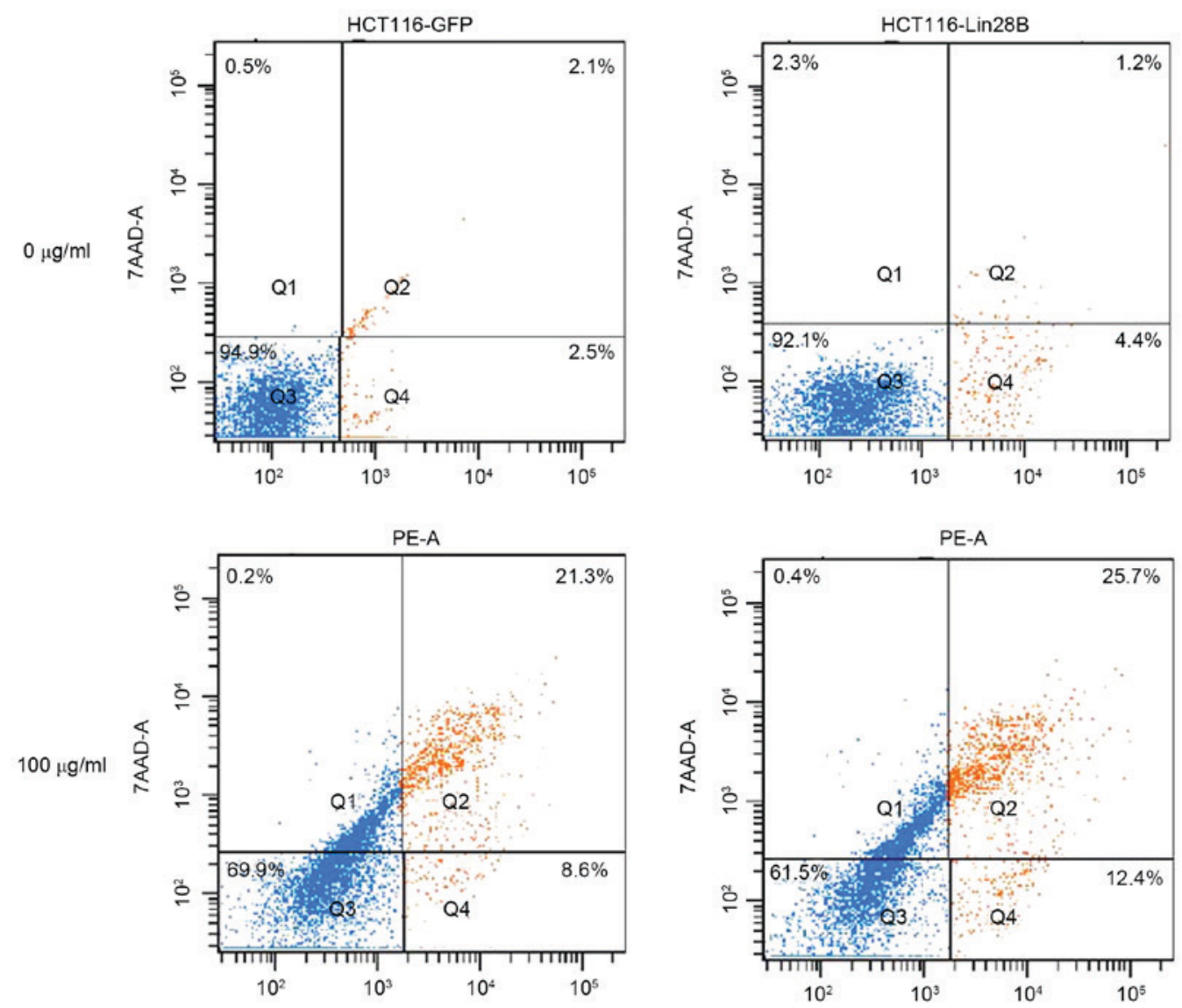

Figure 3. Lin28B overexpression promoted the apoptosis of HCT116 cells induced by 5-FU. Lin28B, Lin-28 homolog B. 


\section{Discussion}

The RNA-binding Lin28 protein family consists of two members, Lin28A and Lin28B. Lin28A was initially known as a developmental timing regulator and functions as a stemness maintenance factor, whereas Lin28B was first identified in hepatocellular carcinoma $(4,15,16)$. Both proteins have been demonstrated to block the biogenesis of microRNA let-7s by interacting with primary or precursor let-7s and preventing their maturation or inducing their degradation (3). Previous studies have demonstrated that Lin28A and Lin28B are each frequently upregulated in various malignancies, and the overexpression of Lin28A and Lin28B is associated with multiple biological behaviors of cancers and poor prognosis $(6,17)$. However, few studies have focused on the role of Lin28A or Lin28B in cancer chemotherapy.

The present study showed that Lin 28B was upregulated in all assessed colon cancer tissues. Differing from a previous study (3), it was found that Lin28B was mainly expressed in the cytoplasm instead of the nucleus of colon cancer cells. To the best of our knowledge, the present study is the first to report the cytoplasmic distribution of Lin28B in colon cancer cells. Since a previous study demonstrated that Lin28B expression is associated with an advanced stage of malignant tumors (18), the present study hypothesized that the elevated expression of Lin28B in colon cancer may also act as an oncogene. However, the association analysis between Lin28B expression and clinical characteristics indicated that Lin28B expression level is not associated with tumor growth and metastasis. The function of Lin28B in the chemosensitivity of colon cancer cells was then evaluated. Notably, it was identified that the overexpression of the Lin28B gene, which has oncogenic potential, enhanced the sensitivity of colon cancer HCT116 cells to 5-FU. Additional investigation showed that enforced expression of Lin28B promoted the apoptosis of colon cancer cells induced by 5 -FU. The present results are consistent with a previous study by Teng et al (19), who revealed that Lin28B expression was significantly increased in gastric cancer patients with pathological response to neoadjuvant chemotherapy, which indicated that Lin28B expression is associated with the sensitivity of neoadjuvant chemotherapy in gastric cancer. However, the effect of Lin 28 on chemotherapy in other types of cancer may vary. The promotion of resistance of breast cancer cells to paclitaxel by overexpression of Lin28 has been reported, and the induction of $\mathrm{p} 21$ and $\mathrm{Rb}$ expression and inhibition of let-7a miRNA generation contributes to Lin28-mediated resistance to chemotherapy in breast cancer (20). Additionally, Lin28B-inducedpromotion of chemoresistance to paclitaxel was also reported in hepatocellular carcinoma (21). Investigation of the mechanism revealed that inhibition of let-7 production and the consequent upregulation of its target B-cell lymphoma-extra large underlined the paclitaxel resistance in HCC cells (21). The role of Lin28B in the chemosensitivity of colon cancer cells in the present study differs from the observations in these previous studies. The mechanism of the opposing roles of Lin28B in chemotherapy in different cancer types requires additional experiments to evaluate.

Let-7 is a well-known target of Lin28B, and based on current studies, the majority of the reported functions of Lin28B are associated with the repression of let-7
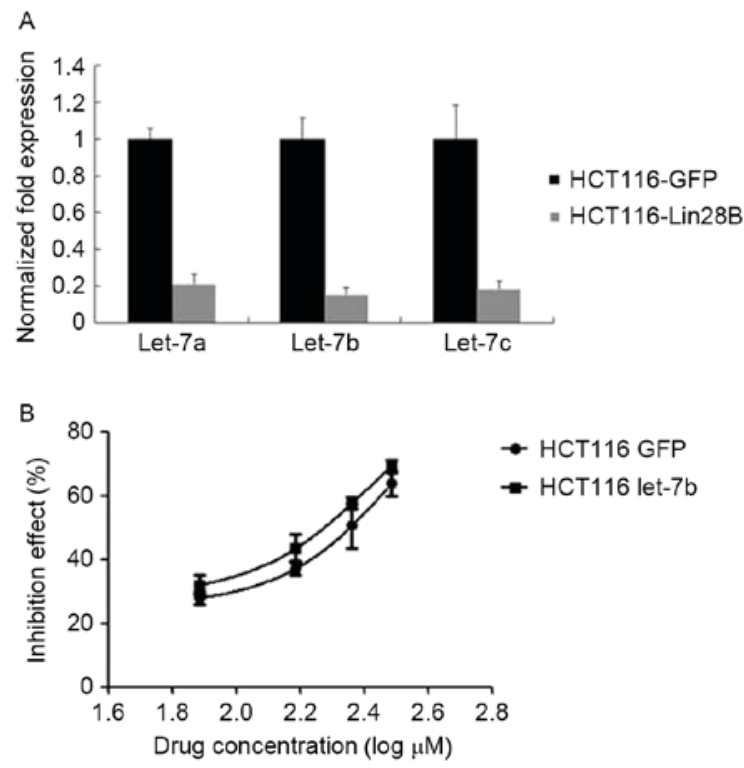

Figure 4. Lin28B increased the chemosensitivity of HCT116 cells to 5-FU in a let-7-independent manner. (A) The overexpression of Lin28B in HCT116 cells repressed the expression of let-7a, let-7b and let-7c, as determined by quantitative polymerase chain reaction. (B) The overexpression of let-7 significantly enhanced the chemosensitivity of HCT116 cells to 5-FU $(\mathrm{P}<0.05)$. Lin28B, Lin-28 homolog B; 5-FU, 5-fluorouracil; GFP, green fluorescent protein

production (6). By binding either pri-let-7 or pre-let-7 and blocking their processing by Drosha or Dicer, or by recruiting TUT4/TUT7 to oligo-uridylate the of pre-let-7, Lin28B negatively regulates the generation of let-7 miRNAs (22-27). In the present study, it was also shown that the over-expression of Lin28B in colon cancer cells significantly attenuated the let-7 level, which is consistent with previous studies $(3,4,8,9)$. To detect the molecular mechanism of Lin28B in promoting chemosensitivity of colon cancer cells to 5-FU, the effect of let-7 in the chemosensitivity of colon cancer cell to 5 -FU was also evaluated. The results showed that the overexpression of let-7b significantly increased the chemosensitivity of colon cancer cells to 5-FU, which indicated that the Lin28B-induced promotion of chemosensitivity of chemosensitivity of colon cancer cells to 5-FUis independent of let-7. The mechanism of this effect of Lin28B on the chemosensitivity of cells requires additional investigation.

In conclusion, the present study showed that overexpression of the oncogene Lin28B increased the chemosensitivity of colon cancer cells to 5-FU by promoting cell apoptosis. Additional investigation indicated that this effect of Lin28B-induced enhancement of chemosensitivity was let-7-independent. The present results indicated that Lin28B may act as a predictive biomarker for chemotherapy in patients with colon cancer.

\section{Acknowledgments}

Not applicable.

\section{Funding}

The present study was supported financially by the National Natural Science Foundation of China (grant no. 81672428). 


\section{Availability of data and materials}

The datasets used and/or analyzed during the current study are available from the corresponding author on reasonable request.

\section{Authors' contributions}

LM and YZ conceived and designed experiments. LM, QZ and WC conducted the experiments and collected data. LM and QZ analyzed data. LM wrote the manuscript and was responsible for manuscript revisions and $\mathrm{YZ}$ assisted with constructive discussions. All authors read and approved the final manuscript.

\section{Ethics approval and consent to participate}

The present study was approved by the ethics committee of Tumor Hospital Affiliated to Harbin Medical University. All participants provided written informed consent.

\section{Consent for publication}

All study participants provided informed consent for the publication of this data.

\section{Competing interests}

The authors declare no conflict of interest.

\section{References}

1. Ferlay J, Shin HR, Bray F, Forman D, Mathers C and Parkin DM: Estimates of worldwide burden of cancer in 2008: GLOBOCAN 2008. Int J Cancer 127: 2893-2917, 2010.

2. Guo Y, Chen Y, Ito H, Watanabe A, Ge X, Kodama T and Aburatani H: Identification and characterization of lin-28 homolog B (LIN28B) in human hepatocellular carcinoma. Gene 384: 51-61, 2006.

3. Piskounova E, Polytarchou C, Thornton JE, LaPierre RJ, Pothoulakis C, Hagan JP, Iliopoulos D and Gregory RI: Lin28A and Lin28B inhibit let-7 microRNA biogenesis by distinct mechanisms. Cell 147: 1066-1079, 2011.

4. King CE, Cuatrecasas M, Castells A, Sepulveda AR, Lee JS and Rustgi AK: LIN28B promotes colon cancer progression and metastasis. Cancer Res 71: 4260-4268, 2011.

5. Hamano R, Miyata H, Yamasaki M, Sugimura K, Tanaka K, Kurokawa Y, Nakajima K, Takiguchi S, Fujiwara Y, Mori M and Doki Y: High expression of Lin28 is associated with tumour aggressiveness and poor prognosis of patients in oesophagus cancer. Br J Cancer 106: 1415-1423, 2012.

6. Tummala R, Nadiminty N, Lou W, Zhu Y, Gandour-Edwards R, Chen HW, Evans CP and Gao AC: Lin28 promotes growth of prostate cancer cells and activates the androgen receptor. Am J Pathol 183: 288-295, 2013.

7. Wang T, Wang G, Hao D, Liu X, Wang D, Ning N and Li X: Aberrant regulation of the LIN28A/LIN28B and let-7 loop in human malignant tumors and its effects on the hallmarks of cancer. Mol Cancer 14: 125, 2015.

8. Pang M, Wu G, Hou X, Hou N, Liang L, Jia G, Shuai P, Luo B, Wang K and Li G: LIN28B promotes colon cancer migration and recurrence. PLoS One 9: e109169, 2014.
9. King CE, Wang L, Winograd R, Madison BB, Mongroo PS, Johnstone CN and Rustgi AK: LIN28B fosters colon cancer migration, invasion and transformation through let-7-dependent and -independent mechanisms. Oncogene 30: 4185-4193, 2011.

10. Zhao R, Wu Y, Wang T, Zhang Y, Kong D, Zhang L, Li X, Wang G, Jin Y, Jin X and Zhang F: Elevated Src expression associated with hepatocellular carcinoma metastasis in northern Chinese patients. Oncol Lett 10: 3026-3034, 2015.

11. Li X, Zhang J, Gao L, McClellan S, Finan MA, Butler TW, Owen LB, Piazza GA and Xi Y: MiR-181 mediates cell differentiation by interrupting the Lin 28 and let-7 feedback circuit. Cell Death Differ 19: 378-386, 2012.

12. Xi Y, Nakajima G, Gavin E, Morris CG, Kudo K, Hayashi K and $\mathrm{Ju} \mathrm{J}$ : Systematic analysis of microRNA expression of RNA extracted from fresh frozen and formalin-fixed paraffin-embedded samples. RNA 13: 1668-1674, 2007.

13. Livak KJ and Schmittgen TD: Analysis of relative gene expression data using real-time quantitative PCR and the 2(-Delta Delta C(T)) method. Methods 25: 402-408, 2001.

14. Wang T, Han P, He Y, Zhao C, Wang G, Yang W, Shan M, Zhu Y, Yang C, Weng M, et al: Lin28A enhances chemosensitivity of colon cancer cells to 5-FU by promoting apoptosis in a let-7 independent manner. Tumour Biol 37: 7657-7665, 2016.

15. Horvitz HR and Sulston JE: Isolation and genetic characterization of cell-lineage mutants of the nematode Caenorhabditis elegans. Genetics 96: 435-454, 1980.

16. Ambros V and Horvitz HR: Heterochronic mutants of the nematode Caenorhabditis elegans. Science 226: 409-416, 1984.

17. Malik F, Korkaya H, Clouthier SG and Wicha MS: Lin28 and HER2: Two stem cell regulators conspire to drive aggressive breast cancer. Cell Cycle 11: 2780-2781, 2012.

18. Viswanathan SR, Powers JT, Einhorn W, Hoshida Y, Ng TL, Toffanin S, O'Sullivan M, Lu J, Phillips LA, Lockhart VL, et al: Lin 28 promotes transformation and is associated with advanced human malignancies. Nat Genet 41: 843-848, 2009.

19. Teng RY, Zhou JC, Jiang ZN, Xu CY, Li ZD, Wang QC, Xu CP, Guo JF, Shen JG and Wang LB: The relationship between Lin28 and the chemotherapy response of gastric cancer. Onco Targets Ther 6: 1341-1345, 2013.

20. Lv K, Liu L, Wang L, Yu J, Liu X, Cheng Y, Dong M, Teng R, Wu L, Fu P, et al: Lin28 mediates paclitaxel resistance by modulating $\mathrm{p} 21, \mathrm{Rb}$ and Let-7a miRNA in breast cancer cells. PLoS One 7: e40008, 2012.

21. Tian N, Han Z, Li Z, Zhou M and Fan C: Lin28/let-7/Bcl-xL pathway: The underlying mechanism of drug resistance in Hep3B cells. Oncol Rep 32: 1050-1056, 2014.

22. Piskounova E, Viswanathan SR, Janas M, LaPierre RJ, Daley GQ, Sliz P and Gregory RI: Determinants of microRNA processing inhibition by the developmentally regulated RNA-binding protein Lin28. J Biol Chem 283: 21310-21314, 2008.

23. Hagan JP, Piskounova E and Gregory RI: Lin 28 recruits the TUTase Zcchc11 to inhibit let-7 maturation in mouse embryonic stem cells. Nat Struct Mol Biol 16: 1021-1025, 2009.

24. Heo I, Joo C, Kim YK, Ha M, Yoon MJ, Cho J, Yeom KH, Han J and Kim VN: TUT4 in concert with Lin28 suppresses microRNA biogenesis through pre-microRNA uridylation. Cell 138: 696-708, 2009.

25. Heo I, Joo C, Cho J, Ha M, Han J and Kim VN: Lin28 mediates the terminal uridylation of let-7 precursor MicroRNA. Mol Cell 32: 276-284, 2008.

26. Chang HM, Triboulet R, Thornton JE and Gregory RI: A role for the Perlman syndrome exonuclease Dis 312 in the Lin28-let-7 pathway. Nature 497: 244-248, 2013.

27. Mullen TE and Marzluff WF: Degradation of histone mRNA requires oligouridylation followed by decapping and simultaneous degradation of the mRNA both $5^{\prime}$ to $3^{\prime}$ and $3^{\prime}$ to $5^{\prime}$. Genes Dev 22: 50-65, 2008. International (CC BY-NC-ND 4.0) License. 